\title{
Rapid ecological isolation and intermediate genetic divergence in lacustrine cyclic parthenogens
}

Katie S Costanzo*1,2 and Derek J Taylor ${ }^{1}$

\begin{abstract}
Background: Ecological shifts can promote rapid divergence and speciation. However, the role of ecological speciation in animals that reproduce predominantly asexually with periodic sex and strong dispersal, such as lacustrine cladocerans, is poorly understood. These life history traits may slow or prevent ecological lineage formation among populations. Proponents of the postglacial ecological isolation hypothesis for Daphnia suggest that some species have formed postglacially in adjacent, but ecologically different habitats. We tested this hypothesis with ecological, morphological, and multilocus coalescence analyses in the putative lacustrine sister species, Daphnia parvula and Daphnia retrocurva.
\end{abstract}

Results: Daphnia parvula and D. retrocurva showed strong habitat separation with rare co-occurrence. Lakes inhabited by $D$. parvula were smaller in size and contained lower densities of invertebrate predators compared to lakes containing $D$. retrocurva. In the laboratory, D. retrocurva was less vulnerable to invertebrate predation, whereas $D$. parvula was less vulnerable to vertebrate predation and was smaller and more transparent than D. retrocurva. The species are significantly differentiated at mitochondrial and nuclear loci and form an intermediate genetic divergence pattern between panmixia and reciprocal monophyly. Coalescence and population genetic modelling indicate a Late or Post Glacial time of divergence with a demographic expansion.

Conclusions: Despite their young age and mixed breeding system, D. parvula and D. retrocurva exhibit significant ecological and genetic divergence that is coincident with the formation of deep temperate glacial lakes. We propose that predation may have facilitated the rapid divergence between D. parvula and D. retrocurva and that intermediate divergence of aquatic cyclic parthenogens is likely more common than previously thought.

\section{Background}

Divergent selection for different habitats has long been proposed as a contributing factor to the evolution of species [1-4]. Regardless of geographic associations, ecological speciation from strong single selective agents, such as predation, or from the additive effects of multiple selective agents (i.e., the niche dimensionality hypothesis) now have empirical support [5-10]. A remaining theoretical gap is a detailed understanding of the role of the breeding system in speciation [11-14]. Although many eukaryotic taxa reproduce both sexually and asexually [13], there are still few empirical studies of speciation beyond strictly

* Correspondence: kscosta@gmail.com

1 Department of Biological Sciences, The State University of New York at Buffalo, Buffalo, NY, 14260, USA

Full list of author information is available at the end of the article sexual taxa [14-17]. Because many organisms with mixed breeding systems are excellent dispersers [18-21], breeding systems with even a small amount of sexual reproduction should suffer homogenization of ecologically differentiated lineages $[11,12,15,22]$. Thus, taxa with mixed breeding systems coupled with high dispersal should possess a weak capacity for rapid ecological radiation compared to strict asexuals and sexuals [11,23-26]. Others, however, have proposed that priority effects where early colonization offers an advantage and divergent selection are frequently strong enough to overcome the homogenizing effects of such mixed breeding systems [22-27].

Cladocerans contain several candidate groups for detailed empirical study of ecological and genetic divergence in a system characterized by both sexual and asex- 
ual reproduction (cyclic parthenogenesis). These microcrustaceans often inhabit insular freshwater systems (i.e. lakes, ponds, reservoirs) with a mosaic of selective regimes through many environmental factors such as ephemerality, temperature, nutrient availability, competition, and predation [28-30]. For example, a common contrast occurs between lakes with visual vertebrate predators that can select for smaller prey species, and lakes dominated by gape-limited invertebrate predators that favor cladoceran communities dominated by large or helmeted species [31-36], as prey vulnerability is a function of prey size relative to predator size. Predation has been proposed to drive evolutionary divergence in morphology and behaviour [32,37-41] and speciation in cladocerans [23,25,26,41-43]. Still, there is little knowledge of ecological speciation among sister species of lacustrine cladocerans, where sexual reproduction is relatively infrequent.

The cladocerans, Daphnia parvula Fordyce, 1901 and Daphnia retrocurva Forbes, 1882 (Fig. 1), provide an opportunity to study the role of ecological factors in promoting rapid divergence in potentially young lacustrine taxa with a mixed breeding system. Although there is variation in the frequency of sex among populations, both species typically reproduce predominantly by clonal asexual reproduction with a few periodic episodes of sex throughout the season [42,44-47]. In North America, D. retrocurva has a more northerly distribution occurring from the central midwest through northern Canada, whereas D. parvula occurs from South America through the southern parts of Canada. However, the species overlap largely near the southern extent of the glacial lake zone in North America where rare co-occurrence is documented (Fig. 2), [42,48-50]. Brooks [42] proposed that

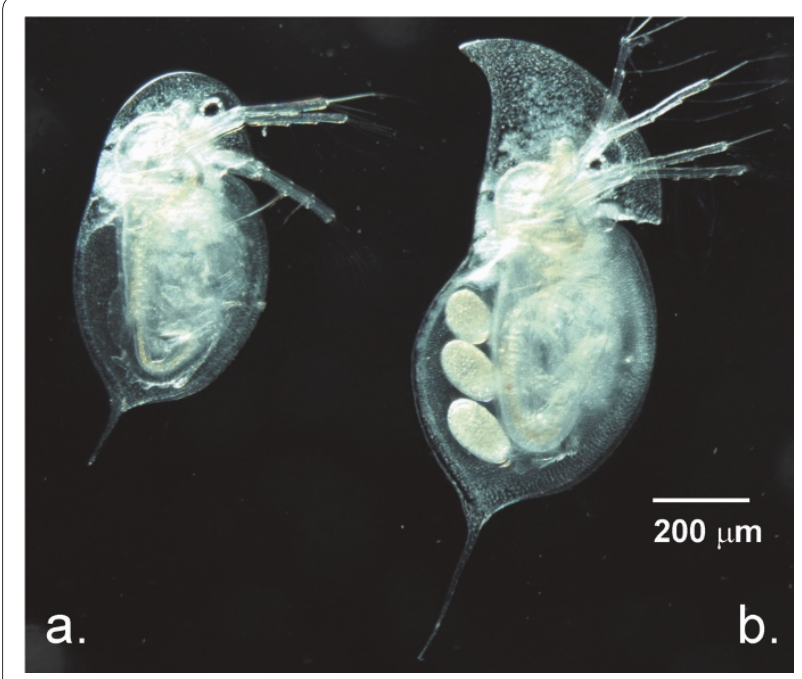

Figure 1 (a.) Daphnia parvula adult female, (b.) Daphnia retrocurva adult gravid female.

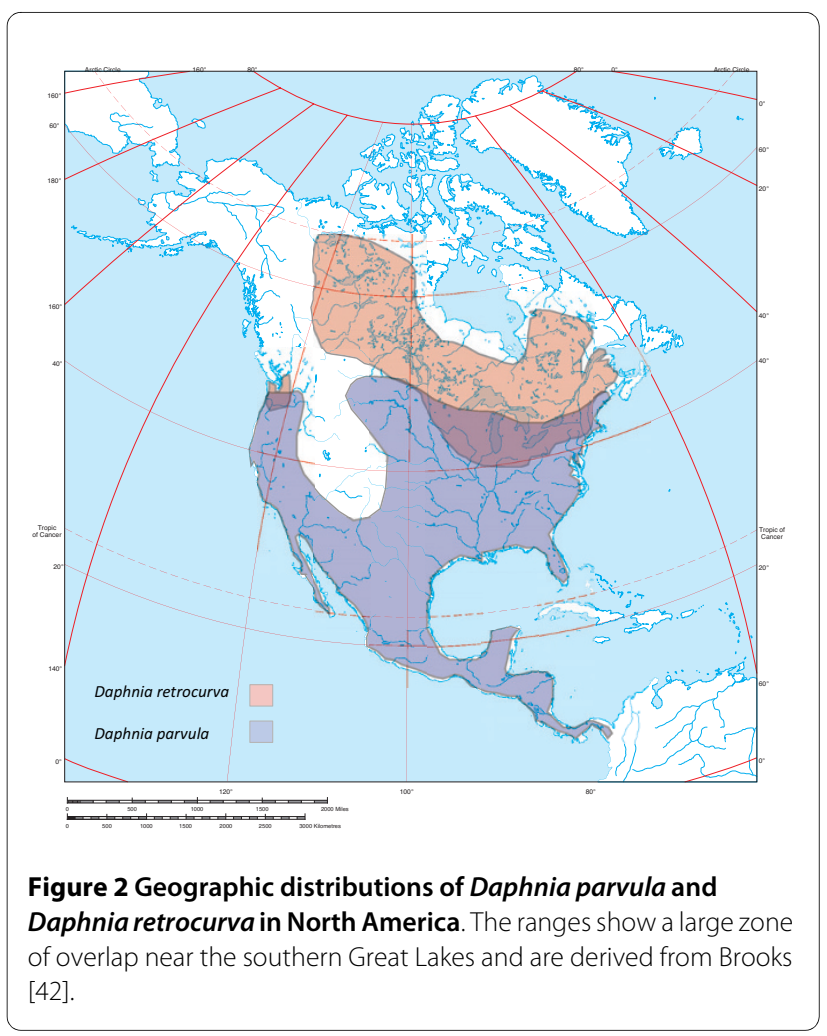

more northerly $D$. retrocurva is a postglacial derivative of $D$. parvula based on their distribution and D. retrocurva inhabiting more novel post-glacial large lake habitats. The two species have a sister group relationship, but no multi-population genetic studies or detailed studies of genetic divergence have been carried out [51-54].

Daphnia parvula lacks the anterior retrocurved helmet (Fig. 1) that appears to be controlled by polyploid cells in the head region of $D$. retrocurva [55]. The helmet undergoes cyclomorphosis in $D$. retrocurva [32,56-60], which can be enhanced by cues from invertebrate predators [32,58-60] and laboratory studies also show decreased vulnerabilities of $D$. retrocurva to invertebrate predation with increased helmet size [61]. Importantly, multigenerational lab culture experiments failed to convert the head shape of $D$. retrocurva into the non-helmeted head shape of $D$. parvula $[56,62,63]$. Although the body size and tail spine length in $D$. parvula can be influenced by predator cues, attempts to induce helmet production have also been unsuccessful [59], suggesting the morphological differences between these two species likely has a genetic component. Additionally, although $D$. retrocurva is a classic example of seasonal polymorphism, experiments reveal that phenotypic plasticity also fails to explain the morphological differences between the two species $[62,63]$.

Although there are no studies that specifically address ecological differentiation between $D$. retrocurva and $D$. 
parvula, there is substantial evidence that the interaction of predation with helmet phenotypes is evolutionarily and ecologically relevant. Kerfoot and Weider [63] for example, show that the abundance of $D$. retrocurva and larger size classes of helmets in D. retrocurva, are positively associated with the increased abundance and size of the invertebrate cladoceran predator, Leptodora, and reduced levels of planktivorous fish over time. Likewise, following the introduction of Leptodora in a lake, a shift from $D$. parvula (without the helmet) was observed to helmeted or large Daphnia [35], suggesting a role for predation as a selective agent for helmets. In contrast, a sixteen-year study [64] found repeated smooth, continuous transitions between large bodied Daphnia and small Daphnia (including D. parvula) associated with planktivorous fish density. Additionally, the abundance of $D$. retrocurva in glacial lakes is positively correlated with the abundance of invertebrate predators, and the abundance of introduced $D$. parvula is negatively associated with rates of invertebrate predation during a season [47]. Taken together, the translocation and natural experiments are consistent with divergent selection from predation playing an isolating role, which could also affect genetic differentiation. However, Lukaszewski et al. [65] found evidence that ecological conditions beyond predation can prevent the successful colonization of D. retrocurva into a lake containing D. parvula.

Isolation affects population genetic patterns in a time dependent fashion. Omland et al. [66] defined "intermediate divergence" as the stages between panmixis and reciprocal monophyly. The lineage divergence continuum, as visualized by networks, begins with gene frequencies diverging with only older internal haplotypes shared (less frequent haplotypes arising since isolation are private), followed by a lack of haplotype sharing. Eventually, population-specific clades (monophyly or paraphyly) are formed. In post-glacial isolation, which has been proposed by Brooks for D. parvula and D. retrocurva [42], such intermediate divergence is often produced and haplotype sharing is limited to the older central haplotypes of the networks [67-69]. In contrast, if isolation is caused by multiple glacial refugia during the late Pleistocene, patterns of multiple geographic subclades along with multiple demographic expansions is predicted as observed in other Daphnia $[67,68]$.

Here, we specifically test for ecological and genetic divergence between $D$. parvula and D. retrocurva. Ecological speciation predicts that populations of $D$. parvula and $D$. retrocurva whose ranges overlap will be associated with ecologically different habitats. If predation is a major selective agent, then we should detect differences in the relative vulnerabilities to habitat-specific predators. If the morphotypes of "retrocurva" and "parvula" are isolated, then we expect to detect significant genetic differentia- tion in the zone of overlap. Further, under the postglacial isolation hypothesis, we expect intermediate divergence (lack of monophyly), a lack of multiple demographic expansions, and divergence times from coalescence modelling to be Late or Post-Glacial. We test these objectives through data culled from pre-existing databases, laboratory predation experiments, and population genetic analyses.

\section{Results}

\section{Habitat differentiation}

Of the 64 lakes analyzed from the data collected from the Environmental Protection Agency (EPA) of lakes in the Northeastern United States, 47 contained D. parvula, 16 contained $D$. retrocurva, and one contained both species. The Discriminant Analysis (DA) indicated that abiotic variables significantly discriminated between lakes containing $D$. parvula and lakes containing $D$. retrocurva (Table 1), with lake area, lake depth, and lake volume contributing most to this group separation. The Analysis of Variance (ANOVA) for lake volume was significant $\left(\mathrm{F}_{1,62}\right.$ $=7.36, \mathrm{P}=0.0079)$, with $D$. retrocurva inhabiting lakes of larger volume than those of $D$. parvula $\left(400.35 \times 10^{5} \mathrm{~m}^{3} \pm\right.$

Table 1: Discriminant Analyses on abiotic variables.

\begin{tabular}{lc}
\hline Variable & $\begin{array}{c}\text { Canonical variate } \\
\text { correlation coefficients }\end{array}$ \\
& \\
\hline Calculated Alkalinity (ueq/L) & -0.119 \\
Chlorophyll A (ug/L) & 0.306 \\
lonic Strength (M) & 0.093 \\
Total Nitrogen (ug/L) & 0.273 \\
Total Phosphorus (ug/L) & 0.368 \\
Mean Secchi dish depth (m) & -0.166 \\
pH & -0.149 \\
Total Suspended Solids (ug/L) & 0.220 \\
Turbulence (NTU) & 0.230 \\
Mean Lake Depth (m) & $-\mathbf{0 . 5 5 1}$ \\
Lake Volume (m3) & $-\mathbf{0 . 5 6 2}$ \\
Lake Area (ha) & $-\mathbf{0 . 4 9 3}$ \\
Lake Elevation & -0.197 \\
discriminatribute most to the group separation (lakes inhabited by $D$. \\
land
\end{tabular}


$34 \times 10^{5}, 41.34 \times 10^{5} \mathrm{~m}^{3} \pm 16 \times 10^{4}$, mean \pm 1 standard error, respectively).

Of the 97 lakes analyzed from the Department of Natural Resources (DNR) in Wisconsin, there were 16 lakes with only $D$. parvula, 79 lakes with only $D$. retrocurva, and two lakes with both species. In both co-occurrence lakes, one species dominated while the other was rare or only present in a single sampling period throughout the year.

The DA indicated that invertebrate predators significantly discriminated between lakes inhabited by $D$. parvula and those inhabited by D. retrocurva (Table 2). The abundance of two copepod predators, Acanothocyclops vernalis and Epischura sp. contributed most to this group separation (Table 2). Daphnia retrocurva inhabits lakes with significantly greater abundances of both these invertebrate predators relative to habitats where $D$. parvula resides (Fig. 3).

\section{Laboratory predation experiments}

For the invertebrate predation experiment, there were significant effects of treatment (control or predator), prey species ( $D$. parvula or D. retrocurva), and the interaction on proportion of prey missing (Table 3 ). There was no difference between the proportion of prey missing of the two species in the controls; however, in the predator treatments $D$. parvula suffered significantly higher mortality by Leptodora kindti than did D. retrocurva (Fig. 4a). The predation rate of $L$. kindti on D. parvula was also higher $(0.0381 \pm 0.01)$ than on $D$. retrocurva $(0.01252 \pm$ 0.002), (mean $\pm \mathrm{SE}$ ).

In the vertebrate predation experiment, there were significant effects of treatment (control vs. predator) and treatment by species interaction for the proportion on

Table 2: Discriminant Analyses on invertebrate predator abundances.

\begin{tabular}{|c|c|}
\hline Variable & Canonical variate correlation coefficients \\
\hline A. vernalis & 0.682 \\
\hline M. edax & 0.289 \\
\hline L. kindti & 0.298 \\
\hline C. punctipennis & -0.272 \\
\hline C. flavicans & 0.276 \\
\hline Epischura sp. & 0.561 \\
\hline Wilks' Lambda $P$ & 0.024 \\
\hline \multicolumn{2}{|c|}{$\begin{array}{l}\text { Canonical variate correlation coefficients derived from the } \\
\text { discriminant analysis for abundances for each invertebrate predator } \\
\text { in the DNR dataset and the Wilk's lambda } P \text { value. The variables with } \\
\text { the highest canonical variate correlations (in bold) contribute most } \\
\text { to the group separation (lakes inhabited by } D \text {. parvula or } D \text {. } \\
\text { retrocurva). }\end{array}$} \\
\hline
\end{tabular}

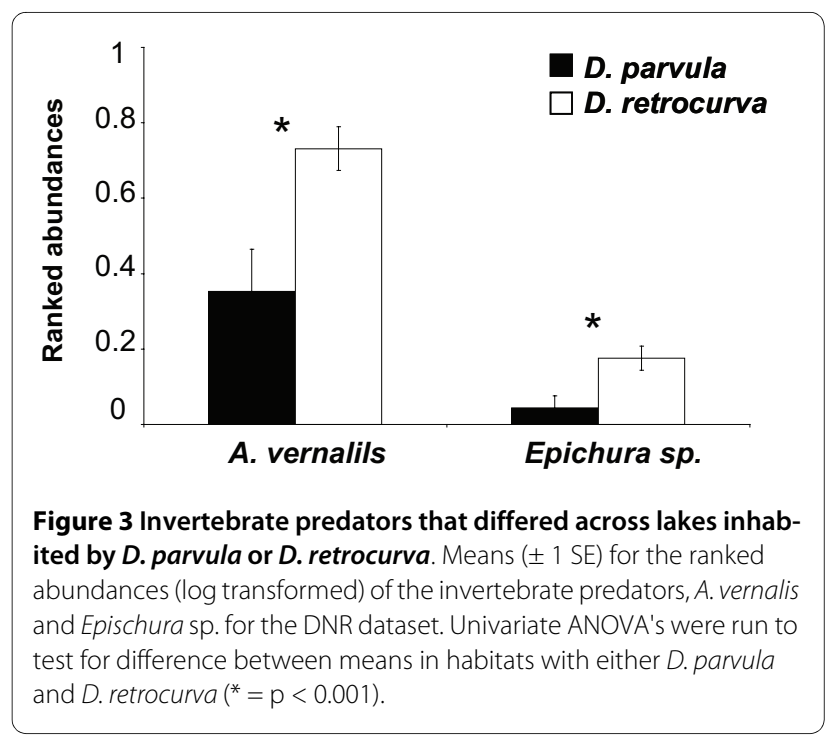

prey missing (Table 3). There was no significant difference between the proportion of prey missing for D. parvula and $D$. retrocurva in the control treatments, but $D$. retrocurva suffered higher mortality by emerald shiners in the predator treatments than did D. parvula (Fig. 4b). The predation rate of the fish on $\mathrm{D}$. retrocurva was also higher $(1.085 \pm 0.0296)$ than that on D. parvula $(0.638 \pm$ 0.033).

For all prey populations used in both predator experiments, the ANOVA's indicated body length, from top of the compound eye to the base of the carapace $\left(\mathrm{F}_{1,98}=\right.$ $75.32, \mathrm{P}<0.001$ ) and total body length, from highest point of helmet or head to the tip of the tailspine $\left(\mathrm{F}_{1,98}=\right.$ 394.42, $\mathrm{P}<0.001)$ were both significant by species. Daphnia parvula was significantly smaller than $D$. retrocurva and this difference is accentuated when including

Table 3: Prey vulnerabilities to tested invertebrate and vertebrate predation.

\begin{tabular}{|c|c|c|c|c|}
\hline \multicolumn{5}{|c|}{ Invertebrate Predation Experiment } \\
\hline Source & $d f$ & MS & $\mathbf{F}$ & $P$ \\
\hline treatment & 1,46 & 2.880 & 65.994 & $<0.001$ \\
\hline species & 1,46 & 0.234 & 5.362 & 0.025 \\
\hline treatment ${ }^{*}$ species & 1,46 & 0.215 & 4.928 & 0.031 \\
\hline
\end{tabular}

Vertebrate Predation Experiment

\begin{tabular}{|c|c|c|c|c|}
\hline treatment & 1,28 & 2.682 & 147.589 & $<0.001$ \\
\hline species & 1,28 & 0.060 & 3.322 & 0.079 \\
\hline treatment ${ }^{*}$ species & 1,28 & 0.114 & 6.287 & 0.031 \\
\hline
\end{tabular}

Results for ANOVA's on the proportion missing prey following the invertebrate and vertebrate predation experiments. 


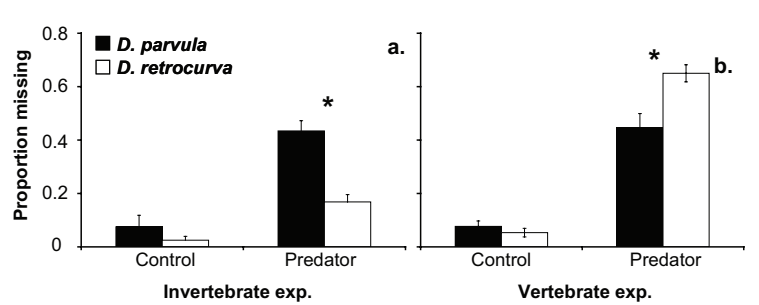

Figure 4 Relative prey vulnerabilities to tested invertebrate and vertebrate predation. Mean proportion of prey missing ( \pm 1 SE) for the a) invertebrate predator experiment, and b) vertebrate predator experiment. Asterisks indicate significant differences $(p<0.001)$ of prey mortality between the prey species used (D. parvula or D. retrocurva).

cyclomorphic features (Fig. 5a). The nested effect of the source population within species (populations used for experiments) was also significant for body length $\left(\mathrm{F}_{2,97}=\right.$ $13.78 \mathrm{P}<0.001)$ and borderline significant for total body length $\left(\mathrm{F}_{2,97}=3.08 \mathrm{P}=0.0508\right)$, indicating that despite much variation across populations, $D$. parvula was consistently smaller than $D$. retrocurva. In addition, $D$. parvula was relatively more transparent than $D$. retrocurva (Fig. 5b), which was still the case when only non-parthenogenic or non-gravid females were analyzed $\left(\mathrm{F}_{1,48}=9.37\right.$, $\mathrm{P}<0.0036$ ).

\section{Genetic analyses}

The tree was comprised of monophyletic subclades of $D$. parvula and D. retrocurva (several with strong support), but there is insufficient information to place the root or to determine if the subclades form reciprocally monophyletic groups (Fig. 6). The genealogical sorting index indicates that the species do form two significantly diverged lineages (Table 4). Mitochondrial and nuclear networks show haplotype sharing but there is differentiation between $D$. parvula and $D$. retrocurva with most of the shared haplotypes having a central or presumed ancestral location (Fig. 7).

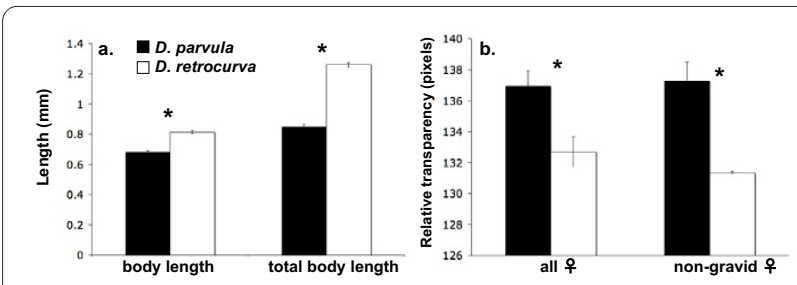

Figure $\mathbf{5}$ Morphological measurements on prey populations. Mean measurements ( $\pm 1 \mathrm{SE}$ ) for a) body length and total body length from populations of $D$. parvula and $D$. retrocurva used in the predation experiments, and b) relative transparency from populations used in the vertebrate predation experiment comparing all females and only non-parthenogenic or non-gravid females. Significant pairwise comparisons are indicated with asterisks. $\left.{ }^{*}=p<0.001\right)$.
Table 4: Detection of exclusive ancestry.

\begin{tabular}{cccc}
\hline Marker & Species & gsi & $\boldsymbol{P}$ \\
& & & \\
\hline Mitochondrial & D. parvula & 0.6174 & $<0.001$ \\
(ND2) & D. retrocurva & 0.7039 & $<0.001$ \\
& & & \\
\hline Nuclear & D. parvula & 0.2574 & $<0.001$ \\
(HSP90, F6F12, G6G12) & D. retrocurva & 0.3982 & 0.016 \\
& & & \\
\hline Total & D. parvula & 0.6614 & $<0.001$ \\
Evidence & D. retrocurva & 0.5836 & $<0.001$ \\
\hline
\end{tabular}

Genealogical sorting index along with the probability statistic testing the null hypothesis that the gene copies labelled $D$. retrocurva and $D$. parvula form a single intermixed group.

The divergence time $(t)$ was estimated to be at 20,600 years ago when the migration prior was set to zero migrants/generation, and 31,000 years ago with a migration prior set at 10 migrants/generation (Fig. 8). When treating the data as a single group, the mismatch distribution was not significantly different from what is expected under a single expansion $(P=0.74)$. The $\tau$ parameter estimating the date initiating the expansion [70] was 4.765 (95th percentile confidence interval 1.57-11.53; Fig. 9) and the demographic expansion within this group was estimated at 11,405 years ago (95th percentile confidence interval range of 4,000 - 26,000 years ago). The mismatch distributions within D. parvula and D. retrocurva were not significantly different from the expected distributions under the expansion model $(\mathrm{P}=0.78, \mathrm{P}=0.1972$, respectively; Fig. 9). The $\tau$ parameter estimating the date initiating the expansion was 5.15 (95th percentile confidence interval 1.78 - 12.91) for D. parvula and 5.84 (95th percentile confidence interval $2.12-4.51$ ) for D. retrocurva. Demographic expansion was estimated at 12,331 years ago (95th percentile confidence interval range of 3,00031,000 years ago) for D. parvula and 13,969 years ago (95th percentile interval range of 5,000 - 35,000) for D. retrocurva.

The results of the Analysis of Molecular Variance (AMOVA) of both the individual markers and all four markers combined indicate a relatively small proportion of the total genetic variation is found between the two species. In addition, the fixation indices demonstrate very high differentiation among populations within a species and within populations (Table 5).

\section{Discussion}

Our findings illustrate rare co-occurrence of D. parvula and $D$. retrocurva in the field with strong spatial segregation in ecologically differentiated lakes supporting eco- 


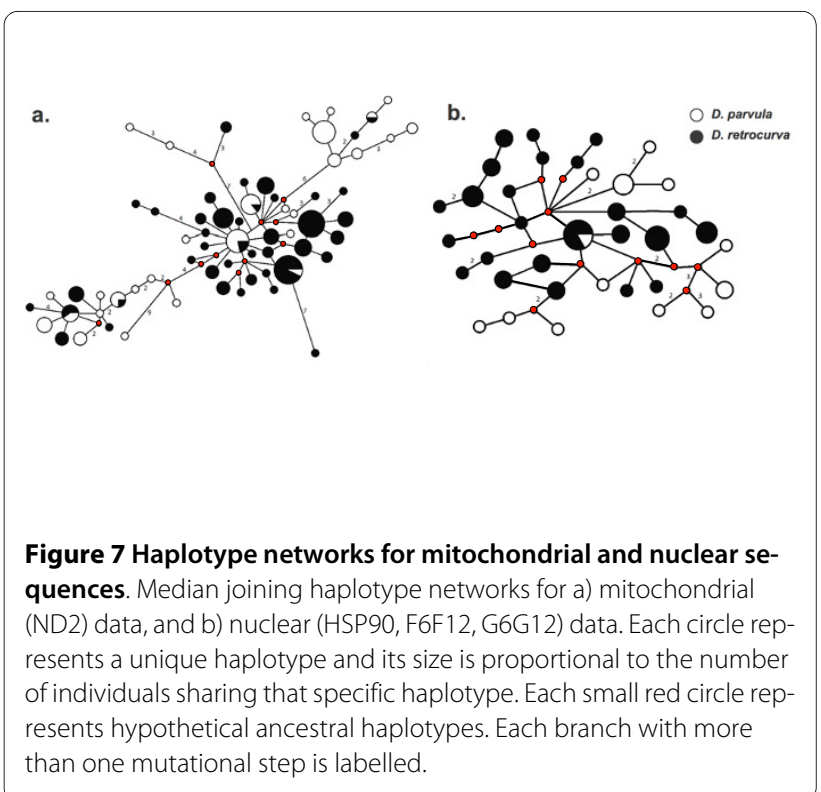

described by Brooks [42] remains mysterious. We failed to detect parvula-like specimens in multiple samples from the same embayment of Lake Ontario examined by Brooks. The rare parvula-like morphs in glacial lakes could be the result of recent inflow from shallow adjacent waters or transient ex-ephippial clones of parvula.

What are the ecological traits associated with isolation? Kerfoot and Weider [63] have elegantly shown that evolution of the helmet size (defensive structures that are the main morphological difference between $D$. retrocurva and $D$. parvula) can be attributed to historical changes in invertebrate predation. Here we show that this process may also contribute to the spatial segregation of these two species in nature, as $D$. retrocurva inhabit larger lakes that contain higher abundances of invertebrate predators relative to lakes where $D$. parvula is found. Although the data collected did not permit us to examine if fish, or vertebrate predators discriminated between the habitats encountered by these two species, the abundance of $D$. parvula has been found to be positively associated with the abundance of planktivorous fish [64]. We also were unable to make a direct association between the abiotic and biotic factors compared in this study since these data were obtained from different sources, yet deeper aquatic habitats can have higher abundances of invertebrate predators of Daphnia because depth affords a refuge from visual predators for conspicuous invertebrate predators [74]. Unexpectedly, the lake data failed to reveal an association between the abundance of Leptodora and Daphnia species. One possible explanation for the lack of association is the difficulty in quantifying abundances of vertically migrating Leptodora in daylight hauls [75-77], yet the abundances of $D$. retrocurva and Leptodora have
Figure 8 Estimates of divergence time. Posterior probabilities of the time of divergence in years of $D$. parvula and $D$. retrocurva when migration priors were set to a) zero migrants/generation, and b) ten migrants/generation. 

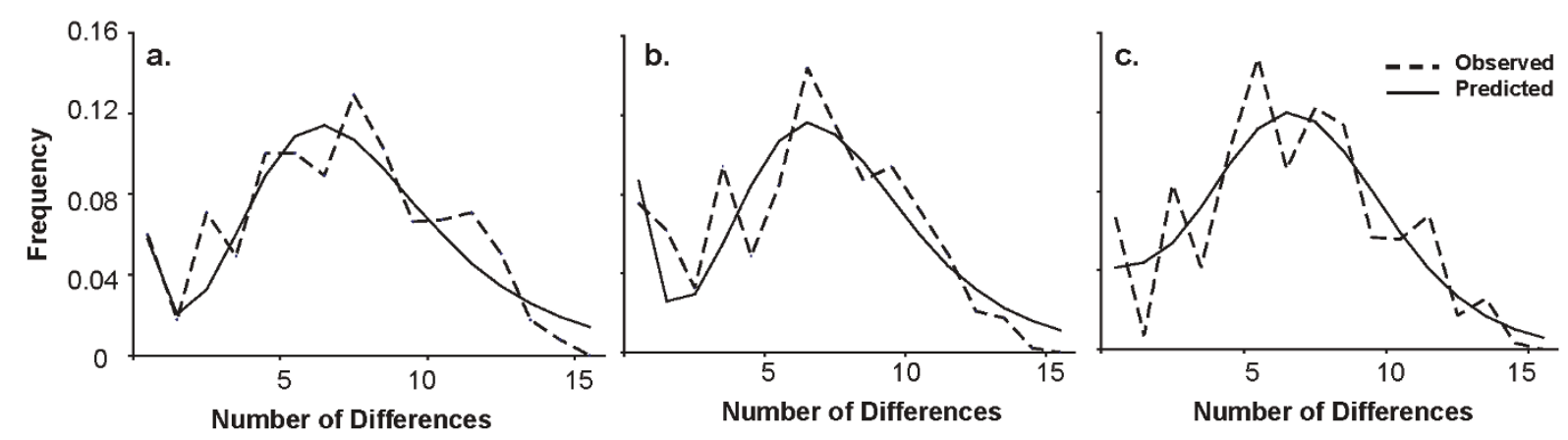

Figure 9 Evidence for demographic expansion. Mismatch distribution plot from mitochondrial data for populations of a) both species, b) D.parvula and c) D. retrocurva. Observed frequencies are dashed lines while predicted frequencies from model are solid lines.

been found to be positively associated in other studies [48].

We also found that $D$. parvula has an advantage relative to $D$. retrocurva in the presence of visual, vertebrate predation which may be a consequence of the smaller body size and greater transparency of D. parvula (Fig. 5). Additionally, D. retrocurva has an advantage over D. parvula in the lab to the invertebrate predator tested. Thus, the present study and existing translocation and longitudinal evidence suggest that $D$. parvula and D. retrocurva have a selective advantage to different habitat-associated predators. It is possible that predation may promote "immigrant inviability" between these two species, or selection against migrants between locally adapted populations, which is a direct result of natural selection reducing gene flow $[78,79]$. The differing predation regimes likely contribute to the spatial segregation of these sister species, but additional local processes may to contribute as well in this system [65]. Our study found that abiotic chemical variables (i.e. nutrients, conductivity) did not discriminate between the two species' habitats, yet other processes that were not included in this study could also contribute to their habitat segregation such as competition, the interactive effects of multiple predators, priority effects, and dispersal [80-83]. Further studies are needed to evaluate the role these other factors may play in facilitating habitat isolation between D. parvula and D. retrocurva, yet evidence suggests that predation is a key factor in determining zooplankton community composition and can reduce the importance of other factors influencing the establishment of Daphnia populations [81,84].

Our results support postglacial genetic divergence between $D$. parvula and $D$. retrocurva despite a mixed breeding system and high dispersal. The networks, single demographic expansion patterns, and divergence estimates based on nuclear and mitochondrial DNA are con-

Table 5: AMOVA results.

\begin{tabular}{|c|c|c|c|c|c|}
\hline Source of Variation & Marker & $d f$ & Diversity Index & \% Variation & $P$ \\
\hline \multirow[t]{3}{*}{ Between species } & ND2 & 1 & 0.1038 & 10.38 & 0.0013 \\
\hline & HSP9O & 1 & 0.2498 & 24.98 & 0.0373 \\
\hline & All 4 markers & 1 & 0.2542 & 25.42 & 0.0079 \\
\hline \multirow[t]{3}{*}{ Among populations within species } & ND2 & 26 & 0.5946 & 49.07 & $<0.001$ \\
\hline & HSP90 & 11 & 0.4286 & 32.15 & $<0.001$ \\
\hline & All 4 markers & 7 & 0.6434 & 47.98 & $<0.001$ \\
\hline \multirow[t]{3}{*}{ Within populations } & ND2 HSP90 All 4 markers & 133 & 0.5476 & 40.54 & $<0.001$ \\
\hline & HSP90 & 31 & 0.5713 & 42.87 & $<0.001$ \\
\hline & All 4 markers & 55 & 0.7341 & 26.59 & $<0.001$ \\
\hline
\end{tabular}

Hierarchal AMOVA results between species, among populations within species and within populations across both markers. 
sistent with intermediate divergence and postglacial isolation. This postglacial timing of divergence is consistent with the origins of the deep temperate glacial lakes $[85,86]$ that constitute the main habitat of $D$. retrocurva. We note that the findings of intermediate divergence do not rule out actual or potential gene flow between $D$. retrocurva and $D$. parvula. The AMOVA reveals a relatively low proportion of the total genetic variation is found between the two species and genetic divergence associated with ecological processes is often characterized by intermediate divergence with ongoing gene flow [87].

Although Daphnia are known to have high dispersal and colonization rates [21], the fixation indices suggest strong genetic differentiation among intraspecific populations (Table 5), suggesting natural selection may also be operating within species as well. Therefore, selection against migrants may lead to a reduction in gene flow in this system on two scales, between two species and the two larger classes of habitat types they reside in, and within a species and the individual local habitat each population resides in. According to island population models, as long as the island population size increases more rapidly than the number of migrants, the per-generation genetic contribution of migrants should decrease and an equilibrium is reached [72] which is likely in Daphnia. Their cyclic parthenogenic reproduction, rapid population growth, and priority effects supported by a large resting bank coupled with local adaptations may allow residents to maintain large populations relative to incoming migrants. Many studies illustrate strong, local adaptations in Daphnia populations and the reduced success of invaders [21,72,81], this high genetic differentiation among intraspecific Daphnia populations often leads to a monopolization effect $[67,72,88,89]$ in which predation, competition, reproduction, ontogeny, and tolerance to eutrophication have been implicated to promote [72,8890].

Conflicting models have been proposed whereby mixed breeding systems either slow [12] or accelerate divergence $[18,23,26]$. In our study, despite their young age, $D$. retrocurva and $D$. parvula illustrate ecological divergence with respect to their habitats, morphology, and predator vulnerabilities suggesting possible selective advantages to each in their respective environments. Both species typically have a mixed breeding system with relatively infrequent sex $[42,44,45,47]$ and illustrate strong dispersal capabilities $[47,64,73]$. Although some believe that populations with mixed breeding systems are less likely to yield discrete or distinct groups relative to populations with strictly sexual or asexual reproduction [12], this study illustrates two groups that have diverged into two distinct lineages and maintained this divergence with a mixed breeding system coupled with high dispersal, and more importantly over a relatively short period of time.
Lynch and Gabriel [89] propose that a single generation of sex can reveal $50-75 \%$ of the genetic variance hidden by asexual reproduction. Therefore, reproduction marked by cyclic parthenogenesis could allow such rapid divergence through the combined benefits of rapid population growth rates that asexual reproduction offers along with the release of genetic variation in the few episodes of sexual reproduction [91]. We postulate this mixed breeding system permits such rapid postglacial divergence of $D$. parvula and $D$. retrocurva, with selection against migrants (immigrant inviability) maintaining this divergence by reducing the homogenizing effects of dispersal.

\section{Conclusions}

We present evidence for rapid ecological, morphological, and genetic divergence of sister species of lacustrine cyclic parthenogens. The species differ in geneticallybased defensive structures and predation regimes. Predation has been implicated as a selective force promoting divergence among taxa in only a few animal lineages. The present study suggests a role for predation in facilitating habitat isolation in young sister species with a mixed breeding system. However, multifarious selection can bring about reproductive isolation more effectively than selection from a single factor, and the habitats of $D$. retrocurva and $D$. parvula differ in numerous ways that could affect selection. Although predation has been implicated as a key factor in determining community composition and establishment of Daphnia [81,84], other factors need to be further evaluated. Our results do indicate that a better understanding of the evolution of the numerous presumed intraspecific defensive-morphotypes of cladocerans is needed. Intermediate divergence of aquatic cyclic parthenogens is likely more common than previously thought.

\section{Methods \\ Habitat differentiation}

We obtained occurrence data from the United States Environmental Protection Agency's (EPA) Environmental Monitoring and Association Proposal (EMAP), http:// www.epa.gov/emap/. These data were collected from 64 lakes and ponds in the northeastern United States in the months of July through September from 1991 to 1994. From this study, data were extracted on the presence or absence of $D$. parvula or $D$. retrocurva within each habitat, along with physical and chemical measurements of: ionic strength $(\mathrm{M}), \mathrm{pH}$, total nitrogen $(\mu \mathrm{g} / \mathrm{L})$, total phosphorus $(\mu \mathrm{g} / \mathrm{L})$, trichomatic chlorophyll A $(\mu \mathrm{g} / \mathrm{L})$, total suspended solids $(\mu \mathrm{g} / \mathrm{L})$, secchi depth $(\mathrm{m})$, calculated alkalinity (meq/L), turbidity (NTU), average depth of lake $(\mathrm{m})$, lake volume $\left(\mathrm{m}^{3}\right)$, lake surface area (ha), and \% of watershed in human disturbed land. The methods used to measure each variable are described at http:// 
www.epa.gov/emap/. We coded the presence/absence data in each site for both $D$. parvula and $D$. retrocurva. There was one lake in the EPA abiotic dataset that included both species, and in this lake $D$. parvula was rare. Data from this co-occurrence lake were removed from the analysis (see below) due to the small sample size.

Separate data collected by the Wisconsin Department of Natural Resources (DNR) [92] from 1973-1974 from 99 lakes throughout Wisconsin were used to test for differences in invertebrate predator assemblages across the species' habitats. We were unable to assess differences between vertebrate predator assemblages (fish) due to incomplete or missing data. Each lake was sampled four times that year (between the months of April through November) where zooplankton and invertebrate predator abundances were recorded. These data include ranked abundances of the following invertebrate predators: the copepods Acanthocyclops vernalis, Epischura sp., and Mesocyclops edax; the larval dipterans Chaoborus flavicans, C. punctipennis, and Chaoborus sp.; and the cladoceran Leptodora kindti. The abundance data were ranked according to the absolute abundances found in the field as follows: $0=$ absent, $1=$ rare ( 3 or less), $2=$ uncommon (4-50), $3=$ common $(51-1,000)$, and $4=$ abundant $(>$ 1000). We coded the presence/absence of D. parvula and $D$. retrocurva. Since the timing of the four periods sampled varied across lakes, the mean values for each lake were used in the analyses. This dataset had two lakes where the species co-occurred (never during the same time period), which were removed from the analysis (see below) due to the small sample size.

Because abiotic and biotic variables are often correlated [28], the datasets were analyzed with a Discriminant Analysis (DA) in SPSS (ver. 11.5, 2006). Two separate DA's were run, one including the abiotic data (EPA) and the other including the biotic data (DNR). Some data were transformed to meet the assumption of normality. We tested whether the variables in a data set (abiotic or biotic) yielded significant discrimination between lakes inhabited by $D$. parvula versus $D$. retrocurva and the correlation of these variables with the discriminant function was used to determine the relative contribution of each variable to the group separation. In the abiotic DA we retrieved three variables that significantly discriminated between lakes inhabited by $D$. parvula or D. retrocurva (lake volume, area, and depth). Since all three variables were mutually correlated, we ran an Analysis of Variance (ANOVA) on lake volume since it had the highest correlation with the discriminant function, with species as the fixed effect. For the invertebrate predators, an ANOVA was used to test for differences between individual predator means indicated by the DA that best discriminate between habitats with $D$. parvula or $D$. retrocurva.

\section{Laboratory predation experiments}

We tested whether $D$. parvula and $D$. retrocurva differ in their vulnerabilities to habitat-specific predators and if they exhibit morphological traits that are known to affect vulnerabilities towards the respective predators. One experiment used an invertebrate predator (Leptodora kindti) while the other a vertebrate predator (emerald shiners, Notropis atherinoides). In addition, morphological measurements were taken of relative body size and transparency for populations used in the predation experiments.

During late summer (August and September) we col-

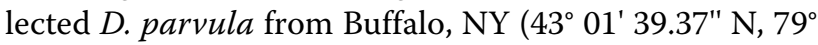
$\left.48^{\prime} 72.39^{\prime \prime} \mathrm{W}\right)$ and $D$. retrocurva from embayments of

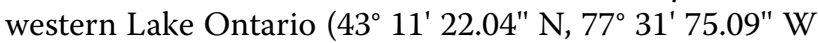
from Irondequoit Bay, NY in August and 43 $17^{\prime} 59.83^{\prime \prime} \mathrm{N}$, $79^{\circ} 48^{\prime} 16.81^{\prime \prime} \mathrm{W}$ from Burlington, Ontario in September). Daphnia was reared for two weeks prior to the experiment at constant densities in 50-ml vials filled with synthetic lake water $\left(96 \mathrm{mg} \mathrm{NaHCO}_{3}, 60 \mathrm{mg} \mathrm{CaSO}{ }_{4} 2 \mathrm{H}_{2} \mathrm{O}\right.$, $60 \mathrm{mg} \mathrm{MgSO}_{4}$ and $4 \mathrm{mg} \mathrm{KCL}$ in $1 \mathrm{~L}$ of double distilled water; EPA 2002) with 10 Daphnia per vial at $21^{\circ} \mathrm{C}$ with a $24 \mathrm{~h}$ light photoperiod. All vials were treated with cetyl alcohol $\left(\mathrm{CH}_{3}\left(\mathrm{CH}_{2}\right)_{15} \mathrm{OH}\right)$ to prevent the Daphnia from getting caught in the surface tension. Every three days, $1000 \mu \mathrm{l}$ of Selenastrum capricornutum suspensions were added to each vial of Daphnia as a food source.

Leptodora kindti was field-collected from Lake Ontario ( $\left.43^{\circ} 11^{\prime} 22.04^{\prime \prime} \mathrm{N}, 77^{\circ} 31^{\prime} 75.09^{\prime \prime} \mathrm{W}\right)$, one week prior to the experiment. Leptodora were individually maintained in $50 \mathrm{ml}$ vials filled with synthetic freshwater at $21^{\circ} \mathrm{C}$ with 24 $\mathrm{h}$ light photoperiod. Every three days $L$. kindti was given zooplankton collected from the field as a food source.

Emerald shiners (from 50 to $64 \mathrm{~mm}$ long in standard length) were obtained from a bait shop and were previously field-collected from the Niagara River, Buffalo, NY. Although the source of these predators were from the Niagara River, emerald shiners are often the dominant planktivorous fish in lakes with Daphnia representing one of their main food sources [93,94]. Prior to the experiment, the fish were kept in $10 \mathrm{~L}$ tanks with treated tap water at room temperature $\left(21^{\circ} \mathrm{C}\right)$ and fed a mix of freshwater fish food (Tetrafin) and zooplankton collected from the field. Both invertebrate and vertebrate predators were starved for 24 hours prior to the experiments.

For the invertebrate predator experiment, all experimental trials took place in $90 \mathrm{ml}$ plastic cups with $50 \mathrm{ml}$ of synthetic fresh water treated with cetyl alcohol 24 hours prior to the experiment. On the day of the experiment, 20 adult female D. parvula (Buffalo population collected in August) or D. retrocurva (Irondequoit Bay population) were added to a cup, which was then randomly assigned 1 or 0 adult $L$. kindti (predator and con- 
trol, respectively). There were 20 replicates of each prey treatment within the predator treatment and 4 replicates of each prey treatment within the control treatment. After 24 hours $\left(21^{\circ} \mathrm{C}, 24 \mathrm{~h}\right.$ light photoperiod) the predator was removed and surviving prey were counted.

For the vertebrate predator experiment, all experimental trials took place in $3.8 \mathrm{~L}$ plastic containers with $3 \mathrm{~L}$ of synthetic lake water at room temperature $\left(21^{\circ} \mathrm{C}\right)$. On the day of the experiment, 50 adult females of either D. parvula (Buffalo population collected in September) or $D$. retrocurva (Burlington population) were added to a container that was randomly assigned 1 or 0 fish (predator and control, respectively). There were 3-4 replicates of the predator treatments and 2 replicates of the control treatments for both prey species on each of 3 days (total: predator 10 replicates, 6 control replicates, for each prey species). The number of replicates in the vertebrate predator experiment was limited by the number of available Daphnia and each replicate used a novel predator. After one hour the predators were removed and the surviving prey were counted.

Prey mortality was equated with the proportion of prey missing. The proportion of prey missing was arcsine square root transformed and analyzed by factorial ANOVA with predator, prey, and the interaction as fixed effects. Post hoc tests with Tukey correction were performed to detect any pairwise differences among mean proportion prey missing between species.

The predation rate coefficient $K$ was calculated in the predator treatments only. We calculated the predation rate coefficient $K$ derived from the Lotka and Volterra equation

$$
\mathrm{dP} / \mathrm{dt}=-K X P,
$$

where $P$ is the number of prey per liter and $X$ is the number of predators per liter. The coefficient $K$ was then calculated by the equation

$$
K=\frac{-\ln \left(P_{\mathrm{T}} / P_{\mathrm{I}}\right)}{\mathrm{XT}}
$$

where $P_{\mathrm{I}}$ is the initial concentration of prey per experimental unit, $P_{\mathrm{T}}$ is the concentration of prey per experimental unit at the end of the trial, $X$ is the number of predators per experimental unit, and $T$ is the duration (in hours) of the trial [95]. Although this equation does not take into consideration reproduction or intrinsic mortality of both prey and predation, in our experiments no reproduction was observed and prey mortality was quantified by the number of prey missing rather than number of dead prey. Although we observed a small proportion of prey missing in the controls treatments, this random effect was likely constant among both control and predator treatment as the higher proportion of prey missing was consistent in the predator treatment replicates.

Following the experiments, morphological measurements were taken on 25 adult females of $D$. parvula and D. retrocurva for each predation experiment (50 total for each species) that were randomly sampled from the laboratory source populations that provided the Daphnia for each predation experiment (individuals from the populations not used in the experiments). From populations from both predation experiments, we measured the body length (from the top of the compound eye to the base of the carapace), and the total body length (from the highest point of the helmet or head to the tip of the tail spine). Measurements were taken with a dissecting microscope and Image (ver. 1.37, 2006). Since D. parvula cannot produce a helmet, these two measurements were used to quantify the body size of $D$. parvula relative to that of $D$. retrocurva, with and without the cyclomorphic features exhibited (helmets and tail spines). We ran separate nested ANOVA's to test for differences in body length and total body length with species as the fixed effect $(D$. parvula or D. retrocurva), and source population nested within species (locality and time collected for either for the invertebrate or vertebrate predation experiment) as a random effect. Both variables were log transformed to meet the assumptions of normality and homogeneity of variances, although raw means are illustrated in the figures.

From populations of $D$. parvula and D. retrocurva used for the vertebrate predation experiment, we additionally quantified the relative transparency using a dissecting microscope and the "Histogram" analysis of ImageJ. Each individual Daphnia was photographed in grey scale under identical magnification and conditions, using only transmitted light. The relative transparency was quantified from the mean pixel intensity ( 0 to 255 for pixel shades from black to white) for the specimen image. Following confirmation that the photo conditions were standardized across both species, an ANOVA was run to test for differences in transparency between $D$. parvula and D. retrocurva. An identical analysis was also run on transparency only among non-gravid females from both species, as the presence of parthenogenic eggs can affect detection of prey by vertebrate predators [96]. All dependent variables were log transformed to meet the assumptions of normality and homogeneity of variances, yet raw means are illustrated in the figures.

\section{Genetic analyses}

Specimens of D. parvula and D. retrocurva were collected from populations $(n=29)$ throughout the continental United States and Canada (see Additional file 1, Table S1). Most populations were from areas in Northern 
United States and southern Canada where the two species' distributions overlap (Fig. 2, Additional file 1: Table S1). We obtained from 1-10 individuals per population (average 5.44 individuals/population).

Total genomic DNA was extracted using Quick Extract (Epicentre). Samples were homogenized in 35-45 $\mu \mathrm{l}$ of Quick Extract solution, then incubated at $65^{\circ} \mathrm{C}$ for $2 \mathrm{~h}$ and $98^{\circ} \mathrm{C}$ for 10 minutes, and stored at $-20^{\circ} \mathrm{C}$. One mitochondrial and three nuclear markers were sequenced from the extracted DNA. A 631 bp fragment of mitochondrial protein-coding NADH-2 (ND2) was amplified with the primers $\left(5^{\prime}\right.$ - GTTCATGCCCCATTTATAGGTTA - 3') and (5'- GAAGGTTTTTAGTTTAGTTAACTTAAAATTCT-3'). The primers (5'TTACGAGTCCAGATGGGCTT-3') and (5'- ATCCGTTATGAATCCCTGACTGA-3') were used to amplify a $669 \mathrm{bp}$ fragment of protein-coding HSP90 gene. A $433 \mathrm{bp}$ fragment of the nuclear rab GTPase (F6F12) gene was amplified with the primers (5'- CGTTTCGAATTGGCTTACTGA-3') and (5'- CATCGTTATCTGTCTACGTCTTGAA-3'), while a $534 \mathrm{bp}$ fragment of the translation initiation factor (G6G12) gene was amplified with the primers (5'- AGAAATTCAACATGCCCAAGA-3') and (5'- CGTCGACGAAGTTGACAGTAT-3') [97]. Each Polymerase Chain Reaction (PCR) was 50-54 $\mu \mathrm{l}$ in total and consisted of 4-8 $\mu \mathrm{l}$ of extracted DNA, $5 \mu \mathrm{l}$ of $10 \times \mathrm{PCR}$ buffer [ $50 \mathrm{mM} \mathrm{KCl}, 1.5 \mathrm{mg} \mathrm{MgCl}_{2}, 10 \mathrm{mM}$ Tris- $\mathrm{HCl} \mathrm{pH}$ 8.3, $0.01 \%$ (w/v) gelatin], $1.5 \mu \mathrm{l}$ of DNTP's ( $2 \mathrm{mM}$ of each), $1 \mu \mathrm{l}$ of $10 \mu \mathrm{M}$ of each primer and $1 \mu \mathrm{l}$ of standard Taq DNA polymerase. Each PCR was conducted on a MJ Thermocycler with the following conditions for the mitochondrial (ND2) gene: 40 cycles at $94^{\circ} \mathrm{C}$ for $30 \mathrm{~s}, 48^{\circ} \mathrm{C}$ for $30 \mathrm{~s}$, and $72^{\circ} \mathrm{C}$ for $1 \mathrm{~min}$, and a final extension at $72^{\circ} \mathrm{C}$ for $7 \mathrm{~min}$. The PCR temperature profiles for the nuclear (HSP90) gene were 40 cycles at $94^{\circ} \mathrm{C}$ for $30 \mathrm{~s}, 50^{\circ} \mathrm{C}$ for $30 \mathrm{~s}$ and $72^{\circ} \mathrm{C}$ for $1 \mathrm{~min}$. with a final extension at $72^{\circ} \mathrm{C}$ for 5 $\mathrm{min}$. For the nuclear (F6F12) gene the PCR temperature profile was 40 cycles at $94^{\circ} \mathrm{C}$ for $30 \mathrm{~s}, 58^{\circ} \mathrm{C}$ for $30 \mathrm{~s}$ and $72^{\circ} \mathrm{C}$ for $1 \mathrm{~min}$. with a final extension at $72^{\circ} \mathrm{C}$ for $5 \mathrm{~min}$, identical temperature profiles were used for the nuclear (G6G12) gene with the exception of the annealing temperature set at $53^{\circ} \mathrm{C}$ rather than $58^{\circ} \mathrm{C}$. Sequences of all nuclear and mitochondrial PCR products were obtained in both directions by Genaissance Pharmaceuticals or the University of Washington and were both assembled and edited with SEQUENCHER ver. 4.2 (Gene Code) then manually aligned in SE-AL 2.0 [98].

An individual was considered heterozygous when overlapping peaks (lower peak > 95\% of higher peak) were observed at any given site on the sequence electropherogram. Individuals with multiple heterozygous sites were cloned with the Invitrogen TOPO TA kit to determine the different alleles at each site with observed heterozygosity. The QIAprep Spin Miniprep Kit (QIAGEN) was used for plasmid purification and the respective primers for each particular locus were used to sequence the cloned inserts. For each individual, six cloned fragments were sequenced to help detect cloning artifacts [99]. The combined data for all four makers was a 2268 bp sequence with both alleles represented for each individual for the nuclear genes. All individuals sequenced for the F6F12 and G6G12 markers were also represented with sequences for the HSP90 and ND2 markers. DNA quality appeared to prohibit sequencing of all genes for all individuals. Therefore, we conducted analyses for 1) individuals represented by sequences for only the mitochondrial ND2 gene, 2) individuals represented by sequences with only the three nuclear genes, and 3) individuals represented by sequences for all four genes (total evidence).

The number of individuals sequenced from each marker used in the analyses can be seen in Additional file 1: Table S1. Each individual was represented by two copies of each sequence to account for both alleles at a heterozygote site in the nuclear markers, while the mitochondrial (ND2) gene was replicated twice to correspond with the two copies of each nuclear gene sequence for the analyses. We performed a phylogenetic analysis on the total evidence data set (all four genes combined) using Maximum Likelihood (ML) method with RAxML [100] and a file to partition the alignment by codon position and gene. For all analyses a GTR substitution model was implemented for the analysis and unique model parameters were optimized and applied for each partition. Support values were estimated using 100 bootstrap replicates.

Because the transition from polyphyly to monophyly is continuous, a categorical description of divergence can fail to identify significant divergence before monophyly is reached [101]. Thus, detecting divergence in closely related or recently diverged species phylogenetically can be difficult if monophyly has not been reached. The recently described Genealogical Sorting Index (gsi) allows one to detect significant genealogical divergence before monophyly by quantifying the relative degree of exclusive ancestry of a labelled group on a rooted tree topology. Since branch tips along a tree generally represent gene copies of a given locus, the value of $g s i$ is the degree of genealogical exclusivity among the sampled gene copies. The calculated $g s i$ value ranges from $0-1$, with 0 representing panmixia and 1 representing monophyly and permutation tests provide a statistical test of significance for this value [101].

We calculated the gsi value for each species (D. parvula and $D$. retrocurva) and tested the null hypothesis that the gene copies labelled $D$. retrocurva and $D$. parvula form a single intermixed group. Because strongly unbalanced group representation can result in a decreased power to detect significant exclusive relationships [101] we deter- 
mined the gsi for the mitochondrial data, the nuclear data, and the total evidence data after randomly removing $D$. retrocurva individuals from the data to achieve a balanced sampling scheme, since this species was over represented compared to $D$. parvula.

A median-joining haplotype network was constructed for the mitochondrial data and the three combined nuclear gene sequence data using NETWORK ver. 4.5.0.0 [102]. In order to further estimate divergence time we used the isolation with migration- analytic (IMa) model, which was designed to analyze recently separated populations (or in this case, species) not at equilibrium. This model estimates six demographic parameters including gene flow rates and time of divergence while generating relative likelihoods/posterior probabilities [103]. Unfortunately we could not get reliable migration or gene flow estimates in IMa likely due to the increased number of parameters in the model (J. Hey communication); therefore, we used IMa solely for estimating divergence time. Since the degree of current gene flow between $D$. parvula and $D$. retrocurva is unknown we ran two IMa analyses, one with the migration prior set to zero migrants per generation and another with ten migrants per generation between the two species which we treated as populations. For both analyses, we used the Hasegawa-Kishino-Yano model [104] and the Infinite Sites mutation model for the mitochondrial and nuclear markers, respectively. The mutation rates entered in the model were the number of bp in the particular marker multiplied by $3.3 \times 10^{-6}$ mutations/site/year for the mitochondrial marker and $1.05 \times$ $10^{-7}$ mutations/site/year for the nuclear markers [105], assuming 5 generations per year; previous estimates adjusted to seasonal duration of localities [106,107]. The analysis included 30 million generations post burn-in (1 million generations) with six Metropolis-coupled Markov chains with the first heating parameter for the linear heating scheme set to 0.05 . Tajima's D test and the fourgamete test (DNASP ver. 4.0) indicate all markers are consistent with the expectations of neutrality and the nuclear markers show no evidence of recombination, both assumptions of the IMa model.

Sequences from the rapidly evolving mitochondrial ND2 gene were used to determine the demographic history of both $D$. parvula and $D$. retrocurva lineages. Three mismatch distributions were calculated from the number of differences between pairs of haplotypes within and between species in ARLEQUIN [108]. The Sum of Square Deviations (SSD) was computed for each species separately then tested whether the observed distributions deviated significantly from those expected under the population expansion model using 10000 permutation replicates. We used the parameter $\tau$ to estimate the time since the expansion $(t)$ using the equation $t=\tau / 2 \mathrm{u}$, where $\mathrm{u}$ is the mutation rate per sequence per generation [109] assuming a mutation rate of $6.6 \times 10^{-8} /$ site/generation [110] and five generations/year.

We ran hierarchical Analysis of Molecular Variance (AMOVA) in ARLEQUIN [108] to determine the total genetic variation explained by differences $(i)$ between the two species $D$. parvula and $D$. retrocurva, $\left(\mathrm{F}_{\mathrm{CT}}\right)$, (ii) among populations within a species, $\left(\mathrm{F}_{\mathrm{SC}}\right)$, and (iii) within a population $\left(\mathrm{F}_{\mathrm{IS}}\right)$.

\section{Additional material}

Additional file 1 Appendix Table S1 - List of populations used in genetic analyses.

\section{Authors' contributions}

KSC and DJT designed the study. KSC performed laboratory experiments, molecular lab work and performed all the analyses. KSC and DJT were both involved in analysis interpretation and manuscript composition. All authors read and approved the final manuscript.

\section{Acknowledgements}

We thank Howard Lasker, Charles Mitchell, Howard Reissen, and Steven Juliano for their comments and suggestions with analyses and interpretation. We also thank Dr. Kenton Stewart, Laura Hovind, Seiji Ishida, and Angela Omilian for assistance with specimen collections, data collection and analyses. This research was supported by an NSF grant (DEB- 0331095) to D. J. T..

\section{Author Details}

'Department of Biological Sciences, The State University of New York at Buffalo, Buffalo, NY, 14260, USA and 2Illinois Natural History Survey, Institute of Natural Resource Sustainability University of Illinois at Urbana-Champaign, IL 61802 USA

Received: 30 October 2009 Accepted: 5 June 2010

Published: 5 June 2010

\section{References}

1. Orr MR, Smith TB: Ecology and speciation. Trends Ecol Evol 1998, 13:502-506

2. Mayr E: Systematics and the origin of species, from the viewpoint of a zoologist. New York: Columbia University Press; 1942.

3. Funk DJ, Nosil P, Etges WJ: Ecological divergence exhibits consistently positive associations with reproductive isolation across disparate taxa. Proc Natl Acad Sci USA 2006, 103:3209-3213.

4. Darwin C: On the origin of the species by means of natural selection, or, The preservation of favoured races in the struggle for life. London: John Murray; 1859.

5. Crispo E, Bentzen P, Reznick D, Kinnison M, Hendry A: The relative influence of natural selection and geography on gene flow in guppies. Mol Ecol 2006, 15:49-62

6. Diabate A, Dabire R, Heidenberger K, Crawford J, Lamp W, Culler L, Lehmann T: Evidence for divergent selection between the molecular forms of Anopheles gambiae: role of predation. BMC Evol Biol 2008, 8:5

7. McPeek M, Wellborn G: Genetic variation and reproductive isolation among phenotypically divergent amphipod populations. Limnol Oceanogr 1998, 43:1162-1169.

8. Nosil P: Reproductive isolation caused by visual predation on migrants between divergent environments. Proc R Soc London B Biol Sci 2004, 271:1521-1528.

9. Nosil P, Harmon L: Niche dimensionality and ecological speciation. In Speciation and patterns of diversity Edited by: Butlin R, Bridle J, Schluter D. Cambridge: Cambridge University Press; 2009:127-154.

10. Rice W, Hostert E: Laboratory experiments on speciation: what have we learned in 40 years? Evolution 1993, 47:1637-1653.

11. Bell G: The poverty of the protists. In Speciation and patterns of diversity Edited by: Butlin R, Bridle J, Schluter D. Cambridge: Cambridge University Press; 2009:46-58. 
12. Coyne J, Orr H: Speciation. Sunderland, MA: Sinauer Associates; 2004.

13. Barraclough TB, Birky CW Jr, Burt A: Diversification in sexual and asexual organisms. Evolution 2003, 57:677-683.

14. Birky CW Jr, Wolf C, Maughan H, Herbertson L, Henry E: Speciation and selection without sex. Hydrobiologia 2005, 181:29-45.

15. Bell $\mathrm{G}$ : The masterpiece of nature: the evolution and genetics of sexuality. Berkely CA: University of California Press; 1982.

16. Fontaneto D, Herniou E, Boschetti C, Caprioli M, Melone G, Ricci C, Barraclough T: Independently evolving species in asexual bdelloid rotifers. PLOS Biol 2007, 5:914-921.

17. Heethoff M, Domes K, Laumann M, Maraun M, Norton RA, Scheu S: High genetic divergences indicate ancient separation of parthenogenetic lineages of the oribatid mite Platynothrus peltifer (Acari, Oribatida). J Evol Biol 2007, 20:392-402.

18. Dickson RC: Aphid dispersal over Southern California deserts. Ann Entomol Soc Am 1959, 52:368-372.

19. Compton SG: Sailing with the wind: dispersal by small flying insects. In Dispersal Ecology Edited by: Bullock JM, Kenward RE. Malden MA: Blackwell Publishing company; 2002.

20. Pourriot R, Snell TW: Resting eggs in rotifers. Hydrobiologia 1983, 104:213-224.

21. Louette G, De Meester L: High dispersal capacity of cladoceran zooplankton in newly founded communities. Ecology 2005, 86:353-359.

22. Mayr E: Animal species and evolution. Cambridge, MA: Harvard University Press; 1963.

23. Duffy MA, Tessier AJ, Kosnik MA: Testing the ecological relevance of Daphnia species designations. Freshwater Biol 2004, 49:55.

24. Lynch M: Speciation in Cladocera. Internationale Vereinigung Fuer Theoretische und Angewandte Limnologie Verhandlungen 1985, 22:3116-3123

25. Pfrender ME, Spitze K, Lehman N: Multi-locus genetic evidence for rapid ecologically based speciation in Daphnia. Mol Ecol 2000, 9:1717-1735.

26. Taylor DJ, Hebert PDN, Colbourne JK: Phylogenetics and evolution of the Daphnia longispina group (Crustacea) based on $12 \mathrm{~S}$ rDNA sequence and allozyme variation. Mol Phylogenet Evol 1996, 5:495-510.

27. Mills S, Lunt D, Gomez A: Global isolation by distance despite strong regional phylogeography in a small metazoan. BMC Evol Bio 2007, 7:225

28. Roff J, Sprules W, Carter J, Dadswell M: The structure of crustacean zooplankton communities in glaciated eastern North America. Can J Fish Aquat Sci 1981, 38:1428-1437.

29. Cottenie K, Nuytten N, Michels E, De Meester L: Zooplankton community structure and environmental conditions in a set of interconnected ponds. Hydrobioloiga 2001, 443:339-350.

30. Wellborn BA, Skelly DK, Werner EE: Mechanisms creating community structure across a freshwater habitat gradient. Ann Rev Ecol Syst 1996 27:337-363.

31. Brooks JL, Dodson SL: Predation, body size, and composition of plankton. Science 1965, 150:28-35.

32. Dodson SI: Adaptive change in plankton morphology in response to size-selective predation: A new hypothesis of cyclomorphosis. Limnol Oceanogr 1974, 19:721-729.

33. Gliwicz ZM, Umaña G: Cladoceran body size and vulnerability to copepod predation. Limnol Oceanogr 1994, 39:419-424.

34. Kerfoot WC: Implications of Copepod Predation. Limnol Oceanogr 1977, 22:316-325.

35. McNaught A, Kiesling R, Ghadouani A: Changes to zooplankton community structure following colonization of a small lake by Leptodora kindti. Limnol Oceanogr 2004, 49:1239-1249.

36. Zaret TM: Predation and freshwater communities. New Haven: Yale University Press; 1980.

37. Cousyn C, De Meester L, Colbourne JK, Brendonck L, Verschuren D, Volckaert F: Rapid, local adaptation of zooplankton behavior to changes in predation pessure in the absence of neutral genetic changes. Proc Natl Acad Sci USA 2001, 98:6256-6260.

38. Fisk D, Latta L, Knapp R, Pfrender M: Rapid evolution in response to introduced predators I: rates and patterns of morphological and lifehistory trait divergence. BMC Evol Biol 2007, 7:22.

39. Jacobs J: Does the high helmet of cyclomorphic Daphnia have an adaptation value? Int Ver Theor Angew Limnol Verh 1962, 15:676-683.

40. Kerfoot WC: Translocation experiments - Bosmina responses to copepod predation. Ecology 1987, 68:596-610.
41. Petrusek A, Tollrian R, Schwenk K, Haas A, Laforsch C: A "crown of thorns" is an inducible defense that protects Daphnia against an ancient predator. Proc Natl Acad Sci USA 2009, 106:2248-2252.

42. Brooks JL: The systematics of North American Daphnia. Mem Conn Acad Arts Sci 1957, 13:1-180

43. Heier C, Dudycha J: Ecological speciation in a cyclic parthenogen: Sexual capability of experimental hybrids between Daphnia pulex and Daphnia pulicaria. Limnol Oceanogr 2009, 54:492-502.

44. Balcer MD, Korda NL, Dodson SI: Zooplankton of the Great Lakes: A guide to the identification and ecology of the common crustacean species. Madison Wl: University of Wisconsin; 1984:62-64.

45. Michaletz PH, Rabeni CF: Factors affecting Daphnia declines in Paddlefish rearing ponds. Porg Fish-Cult 1983, 45:76-80.

46. Pace ML, Porter K, Feig YS: Life history variation within a parthenogenetic population of Daphnia parvula (Crustacea: Cladocera). Oecologia 1984, 63:43-51.

47. Riccardi N, Giussani G, Margaritora F, Couchaud B: Population dynamics of the pioneer population of Daphnia parvula, Fordyce during the invasion of Lake Candia (Northern Italy). J Limnol 2004, 63:44-52.

48. Lennon JT, Smith VH, Williams K: Influence of temperature on exotic Daphnia lumholtzi and implications for invasion success. J Plankon Res 2001, 23:425-433.

49. Pattinson KR, Havel JE, Rhodes RG: Invasibility of a reservoir to exotic Daphnia lumholtzi: experimental assessment of diet selection and life history responses to cyanobacteria. Freshwater Biol 2003, 48:233-346.

50. Keller W, Pitblado J: The distribution of crustacean zooplankton in northern Ontario. J Biogeogr 1989, 16:249-259.

51. Adamowicz S, Petrusek A, Colbourne J, Hebert P, Witt J: The scale of divergence: A phylogenetic appraisal of intercontinental allopatric speciation in a passively dispersed freshwater zooplankton genus. Mol Phylogenet Evol 2009, 50:423-436.

52. Adamowicz SJ, Hebert PDN, Marinone MC: Species diversity and endemism in the Daphnia of Argentina: a genetic investigation. Zool J Linn Soc 2004, 140:171-205.

53. Colbourne JK, Hebert PDN: The systematics of North American Daphnia (Crustacea: Anomopoda): a molecular phylogenetic approach. Philos Trans R Soc Lond B Biol Sci 1996, 351:349-360.

54. Penton EH, Hebert PDN, Crease TJ: Mitochondrial DNA variation in North American populations of Daphnia obtusa: continentalism or cryptic endemism? Mol Ecol 2004, 13:97-107.

55. Beaton MJ, Hebert PDN: The cellular basis of divergent head morphologies in Daphnia. Limnol Oceanogr 1997, 42:346-356.

56. Brooks JL: Cyclomorphosis in Daphnia. 1. An analysis of $D$. retrocurva and D. galeala. Ecol Monogr 1946, 16:409-447.

57. Riessen HP: The Other side of cyclomorphosis: Why Daphnia lose their helmets. Limnol Oceanogr 1984, 29:1123-1127.

58. Burkhardt S: Seasonal size variation in the predatory cladoceran Bythotrephes cederstroemii in Lake Michigan. Freshwater Biol 1994, 31:97-108.

59. Dodson SI: The ecological role of chemical stimuli for the zooplankton: Predator-induced morphology in Daphnia. Oecologia 1989, 78:361-367.

60. Jacobs J: On the regulation mechanism of environmentally controlled allometry (heterauxesis) in cyclomorphic Daphnia. Physiol Zool 1961, 34:202-216

61. Havel JE, Dodson SI: Environmental cues for cyclomorphosis in Daphnia retrocurva. Freshwater Biol 1985, 15:469-478.

62. Banta AM, Wood TR, Brown LA, Ingle L: Studies on the physiology, genetics, and evolution of some Cladocera. Washington, DC: Carnegie Institution of Washington; 1939.

63. Kerfoot W, Weider L: Experimental paleoecology (resurrection ecology): chasing Van Valen's Red Queen hypothesis. Limnol Oceanogr 2004, 49:1300-1316

64. Mittelbach G, Garcia E, Taniguchi Y: Fish reintroductions reveal smooth transitions between lake community states. Ecology 2006, 87:312-318.

65. Lukaszewski Y, Arnott SE, Frost TM: Regional versus local processes in determining zooplankton community composition of Little Rock Lake, Wisconsin, USA. J Plankton Res 1999, 21:991-1003.

66. Omland KE, Baker JM, Peters JL: Genetic signatures of intermediate divergence: population history of Old and New World Holarctic ravens (Corvus corax). Mol Ecol 2006, 15:795-808.

67. Ishida S, Taylor DJ: Mature habitats associated with genetic divergence despite strong dispersal ability in an arthropod. BMCEvol Bio/ 2007, 7:52. 
68. Ishida S, Taylor DJ: Quaternary diversification in a sexual Holarctic zooplankter, Daphnia galeata. Mol Ecol 2007, 16:569-582.

69. McCormack J, Bowen B, Smith T: Integrating paleoecology and genetics of bird populations in two sky island archipelagos. BMC Biol 2008, 6:28.

70. Rogers A, Harpending H: Population growth makes waves in the distribution of pairwise genetic differences. Mol Biol Evol 1992, 9:552-569.

71. Boileau M, Hebert P, Schwartz S: Non-equilibrium gene frequency divergence: persistent founder effects in natural populations. J Evol Biol 1992, 5:25-39.

72. De Meester L, Gomez A, Okamura B, Schwenk K: The Monopolization Hypothesis and the dispersal-gene flow paradox in aquatic organisms. Acta Oecol 2002, 23:121-135.

73. Binks JA, Arnott SE, Sprules WG: Local factors and colonist dispersal influence crustacean zooplankton recovery from cultural acidification. Ecol Appl 2005, 15:2025-2036.

74. Tessier AJWP: Cryptic trophic cascade along a gradient of lake size. Ecology 2002, 83:1263-1270.

75. Chang K, Hanazato T: Diel vertical migrations of invertebrate predators (Leptodora kindtii, Thermocyclops taihokuensis, and Mesocyclops sp.) in a shallow, eutrophic lake. Hydrobiologia 2004, 528:249-259.

76. Costa R, Cummins K: Diurnal vertical migration patterns of Leptodora kindtii (Focke)(Crustacea: Cladocera) in a shallow eutrophic reservoir. Internationale Revue der gesamten Hydrobiologie und Hydrographie 1969, 54:533-541.

77. Cushing D: The vertical migration of planktonic Crustacea. Biol Rev Camb Philos Soc 1951, 26:158-192.

78. Hendry A: Selection against migrants contributes to the rapid evolution of ecologically dependent reproductive isolation. Evol Ecol Res 2004, 6:1219-1236.

79. Nosil P, Vines T, Funk D: Perspective: reproductive isolation caused by natural selection against immigrants from divergent habitats. Evolution 2005, 59:705-719.

80. González MJ, Tessier AJ: Habitat segregation and interactive effects of multiple predators on a prey assemblage. Freshwater Biol 1997, 38:179-191.

81. Louette G, De Meester L: Predation and priority effects in experimenta zooplankton communities. Oikos 2007, 116:419-426.

82. Shurin JB: Interactive effects of predation and dispersal on zooplankton communities. Ecology 2001, 82:3404-3416.

83. Sprules WG: Effect of size-selective predation and food competition on high altitude zooplankton communities. Ecology 1972, 53:375-386.

84. Cottenie K, De Meester L: Metacommunity structure: Synergy of biotic interactions as selective agents and dispersal as fuel. Ecology 2004, 85:114-119.

85. Machereth FJH: Some Chemical Observations on Post-Glacial Lake Sediments. Phil Trans R Soc Lond B 1966, 250:165-213.

86. Clark PU, Dyke AS, Shakun JD, Carlson AE, Clark J, Wohlfarth B, Mitrovica JX, Hostetler W, McCabe AM: The Last Glacial Maximum. Science 2009, 325:710-714.

87. Nosil P, Harmon LJ, Seehausen O: Ecological explanations for (incomplete) speciation. Trends Ecol Evol 2008, 24:145-156.

88. Cousyn C, De Meester L, Colbourne JK, Brendonck L, Vershchuren D, Volckaert F: Rapid, local adaptation of zooplankton behavior to changes in predation pressure in the absence of neutral genetic changes. Proc Natl Acad Sci USA 2001, 98:6256-6260.

89. Lynch W, Gabriel W: Phenotypic evolution and parthenogenesis. Am Nat 1983, 122:745-764.

90. Leibold M, Tessier AJ: Contrasting patterns of body size for Daphnia species that segregate by habitat. Oecologia 1991, 86:348-362.

91. Lynch M: The genetic structure of a cyclical parthenogen. Evolution 1984, 38:186-203.

92. Torke BG: Crustacean zooplankton data for 190 selected Wisconsin inland lakes. Wisconsin Department of Natural Resources Report 1979, 101:1-69.

93. Campbell JS, MacCrimmon HR: Biology of the emerald shiner Notropis atherinoides Rafinesque in Lake Simcoe, Canada. J Fish Biol 1970, 2:259-273.

94. Hartman KJ, Vondracek B, Parrish DL, Muth KM: Diets of emerald and spottail shiners and potential interactions with other western Lake Erie planktivorous fishes. J. Great Lakes Res 1992, 18:43-50.
95. Dodson SI: Predation rates of zooplankton in arctic ponds. Limnol Oceanogr 1975, 20:426-433.

96. Tucker RP, Woolpy SP: The effect of parthenogenic eggs in Daphnia magna on prey location by the bluegill sunfish (Lepomis macrochirus). Hydrobiologia 1984, 109:215-217.

97. Omilian A, Lynch M: Patterns of Intraspecific DNA Variation in the Daphnia Nuclear Genome. Genetics 2009, 182:325-336.

98. Rambaut A: Se-Al: sequence alignment editor v2.0. 1996.

99. Cronn R, Cedroni M, Haselkorn T, Grover C, Wendel J: PCR-mediated recombination in amplification products derived from polyploid cotton. Theor Appl Genet 2002, 104:482-489.

100. Stamatakis A, Hoover P, Rougemont J: A rapid bootstrap algorithm for the RAxML web servers. System Bio/ 2008, 57:758-771.

101. Cummings $M$, Neel M, Shaw K: A genealogical approach to quantifying lineage divergence. Evolution 2008, 62:2411-2422.

102. Bandelt $H$, Forster $P$, Rohl A: Median-joining networks for inferring intraspecific phylogenies. Mol Biol Evol 1999, 16:37-48.

103. Hey J, Nielsen R: Integration within the Felsenstein equation for improved Markov chain Monte Carlo methods in population genetics. Proc Natl Acad Sc USA 2007, 104:2785-2790.

104. Hasegawa M, Kishino H, Yano T: Dating of the human-ape splitting by a molecular clock of mitochondrial DNA. J Mol Evol 1985, 22:160-174.

105. Denver D, Morris K, Lynch M, Thomas W: High mutation rate and predominance of insertions in the Caenorhabditis elegans nuclear genome. Nature 2004, 430:679-682.

106. Dodson SI: Mortality in a population of Daphnia rosea. Ecology 1972 53:1011-1023.

107. Paland S, Colbourne J, Lynch M: Evolutionary history of contagious asexuality in Daphnia pulex. Evolution 2005, 59:800-813.

108. Excoffier L, Laval G, Schneider S: Arlequin (version 3.0): an integrated software package for population genetics data analysis. Evol Bioinform online 2005, 1:47-50

109. Schneider S, Excoffier L: Estimation of past demographic parameters from the distribution of pairwise differences when the mutation rates vary among sites application to human mitochondrial DNA. Genetics 1999, 152:1079-1089.

110. Paland S: Investigations into mitochondrial genome evolution using Daphnia. Bloomington: Indiana University; 2004.

doi: $10.1186 / 1471-2148-10-166$

Cite this article as: Costanzo and Taylor, Rapid ecological isolation and intermediate genetic divergence in lacustrine cyclic parthenogens BMC Evolutionary Biology 2010, 10:166

\section{Submit your next manuscript to BioMed Central and take full advantage of:}

- Convenient online submission

- Thorough peer review

- No space constraints or color figure charges

- Immediate publication on acceptance

- Inclusion in PubMed, CAS, Scopus and Google Scholar

- Research which is freely available for redistribution
C) BioMed Central 